\title{
METHOD OF CALCULATION FLEXURAL STIFFNESS OVER NATURAL OSCILLATIONS FREQUENCIES
}

\author{
A. NESTERENKO ${ }^{1}$, G. STOLPOVSKIY ${ }^{2}$, M. NESTERENKO ${ }^{3}$
}

\begin{abstract}
The actual load-bearing capacity of elements of a building system can be calculated by dynamic parameters, in particular by resonant frequency and compliance. The prerequisites for solving such a problem by the finite element method (FEM) are presented in the article. First, modern vibration tests demonstrate high accuracy in determination of these parameters, which reflects reliability of the diagnosis. Secondly, most modern computational complexes do not include a functional for calculating the load-bearing capacity of an element according to the input values of resonance frequencies. Thirdly, FEM is the basis for development of software tools for automating the computation process. The article presents the method for calculating flexural stiffness and moment of inertia of a beam construction system by its own frequencies. The method includes calculation algorithm realizing the finite element method.
\end{abstract}

Keywords: Dynamics, building system, frequency of natural oscillations, flexural stiffness, finite-element method

\section{INTRODUCTION}

Non-destructive methods for monitoring the operational reliability of building objects are promising [19], one of which is the control of dynamic parameters of building systems. High-precision seismic and vibration digital equipment requisite for registration of oscillatory processes allows obtaining reliable information on the dynamics of structures $[5,7,8,11]$. This information is used to survey the

\footnotetext{
${ }^{1}$ MSc., Postgraduate, Rus., Orenburg Scientific Center of Ural Branch of Russian Academy of Sciences, Geoecology Department, Naberezhnaya 29, 460014 Orenburg, Russia, e-mail: alexnes@mail.ru.

${ }^{2}$ PhD., Assoc. prof., Rus., Orenburg State University, Faculty of Architecture and Civil Engineering, Prosp. Pobedy 13, 466048 Orenburg, Russia, e-mail: stolpovskij@mail.ru

${ }^{3}$ Grand PhD., Prof., Rus., Orenburg Scientific Center of Ural Branch of Russian Academy of Sciences, Geoecology Department, Naberezhnaya 29, 460014 Orenburg, Russia, e-mail: n_mu@mail.ru.
} 
technical condition $[4,7,8]$. The idea of monitoring dynamic parameters of a building system for analysing its internal structure is not new. For example, V. Volkovas $[4,18]$ explore structural defects in buildings using frequency-time analysis and determine in detail the dependence of resonant oscillation frequencies of damaged building frame on the type and direction of the defect. In works $[3,10,15]$ the response to seismic action of various structures with the purpose of their diagnostics is researched.

It's known, that defects and damages of building constructions appearing at an assembling and exploitation stage lead to changes in the resonant frequencies of natural oscillations and damping properties of constructional material of buildings or structures $[7,11,14]$. In particular, the majority of defects reduce the actual values of flexural stiffness as compared with its design value. Natural oscillations of a building system always occur along the most damaged section [5], which makes it possible to estimate the current resource of carrying capacity.

To make the method of stiffness analysis applicable to a wider range of design construction solutions, a study is needed on the application of Finite Element Method (FEM) to calculating stiffness from known frequencies of natural oscillations. For this, it is necessary to calculate the flexural stiffness and the moment of inertia of the cross section of system elements working on flexural under oscillations. That is, the solution of the problem of calculating the resonant frequencies in inverse form. The complexity of such calculations is determined by the need to consider the dynamic work of the entire construction system as a whole and is analogous to direct modelling and calculation of structures with load-bearing capacity. Therefore, the application of FEM method for solving such problems becomes more relevant, because it creates the base for software development for automation of calculations [9]. However, in modern literature there are no studies and recommendations for solving the inverse problem, taking into account the specificity of FEM method. In modern design complexes, such as SCAD Office, ANSYS, LIRA SAPR, etc., there is no suitable functionality that allows ignoring the specification of the cross-section characteristics and introducing the eigenvalue of resonant frequencies for the simulated element.

Thus, the objective of the study is to develop the algorithm for calculating flexural stiffness of building systems by finite element method using natural oscillation frequencies. To achieve this objective it's necessary to solve following tasks:

1. To consider FEM for calculation flexural stiffness from resonant frequencies.

2. To determine an interrelation of compliance in finite elements $(\mathrm{FE})$ of the design scheme of a building system with resonant frequencies.

3. To develop an algorithm for calculating the stiffness at fundamental frequency and at higher frequencies. 
4. To verify the method over numerical experiment with finite element model of beam on two supports.

\section{THE DESCRIPTION OF THE METHOD}

Currently, frequencies of natural oscillations can be determined by finite element displacement analysis [6,12], less often used mixed methods [17] or analytical methods [2]. But for solving problem of calculating flexural stiffness over dynamic tests of structures, it's necessary to get more simple method, which connects frequencies of natural oscillations with stiffness at the point of a system.

Finite element modelling allows considering every mass of a mechanic system as a system with a single degree of freedom but with specific boundary conditions defined by adjacent finite elements. Differential equations of oscillations for a system with a single degree of freedom:

$$
\ddot{\xi}+\omega^{2} \xi=0
$$

where:

$\ddot{\xi}$ - Acceleration of displacement of a mass $m ; \xi$ - displacement of a mass $m ; \omega-$ angular frequency of natural oscillations. $\omega$ is determined as:

$$
\omega=\frac{1}{\sqrt{m \delta}}
$$

where:

$\delta$ - mass displacement under single force. Parameter $\delta$ can also be called as compliance and is connected with stiffness of whole multimass system over boundary conditions.

As it's known fundamental frequency of mechanic system is the lowest one, so in respect with Eq. (2.1) it's necessary to determine mass with maximum value of compliance $\delta$.

Let's consider the solution of inverse problem, considering conclusion above. Inverse problem involves calculation flexural stiffness of a structure system over frequencies of natural oscillations $\omega_{n}$ with the use of FEM. In building constructions with a three-dimensional coordinate system, one linear dimension - length, significantly exceeds the other two. Transverse deformations far exceed longitudinal ones, therefore, when describing oscillatory processes in building constructions, axial compression (extension) is often neglected. Linear stiffness is replaced by a flexural stiffness, 
which is determined as $B=E J$, where $E$ - material module of elasticity; $J$ - moment of inertia of cross-section of flexural element.

The main expression of FEM method is written as follows [1]:

$$
\vec{R}=[K] \vec{q},
$$

where the finite element stiffness matrix $[K]$ connects the joint displacements $\{q\}$ and joint loads of the element $\{R\}$. The physical meaning of elements of stiffness matrix $[K]$ is as follows [1]. The element $K_{i j}$ is numerically equal to the reactive force in the $i$-th direction with a unit displacement along the $j$-th direction $q_{j}=1(i, j=\overline{1, p} ; p-$ is the quantity of possible deformations in $\mathrm{FE}$ system). Each element $K_{i j}$ includes a factor $(E J)_{G}$, which characterizes the flexural stiffness $B_{i}$ of the finite element $G$ in the $i$-th direction. For all directions, flexural stiffness $(E J)_{G}$ of the finite element is the same, and in the inverse problem it is not known. Then, Eq. (2.2) in the expanded form for the case of one FE can be written as [1]:

$$
\left\{\begin{array}{c}
R_{1} \\
R_{2} \\
\cdot \\
R_{p}
\end{array}\right\}=(E J)_{G}\left|\begin{array}{cccc}
K_{11} & K_{12} & \cdot & K_{1 p} \\
K_{21} & K_{22} & \cdot & K_{2 p} \\
K_{p 1} & K_{p 2} & \cdot & K_{p p}
\end{array}\right| \times\left\{\begin{array}{c}
q_{1} \\
q_{2} \\
\cdot \\
q_{p}
\end{array}\right\},
$$

where:

$G$ - number of finite element.

When analyzing the natural oscillations of rod structure systems, the most optimal is the use of beam FE, since it takes into account transverse and angular deformations, and longitudinal ones are not. Filling of local stiffness matrices occurs with force values from the corresponding unit displacements (Fig. 1.a). These values are determined in advance by the force method and are referential (Fig. 1.b).

For each FE flexural stiffness $(E J)_{G}$ will be different, so each new FE of the system will add one variable while formation of global stiffness matrix (GSM) $D \times D(D=2 x S$, where $S-$ is the number of joints in calculation scheme, 2 - accepted number of degrees of freedom in the joint). Thus stiffness values in the common joints (for two adjacent FE) consist of two summands, which are unknown. When solving the inverse problem, the number of values of resonant frequencies exceeds the number of variable stiffness values, thus it is not possible to solve a system of linear algebraic equations. For solution, it is possible to replace the unknown factors $(E J)_{G}$ by a unit factor for all local matrices $(E J)_{A V}$, which will reflect the average flexural stiffness for the whole FE system. After the replacement, we get the global stiffness matrix in a general form (Fig. 2). 
a)

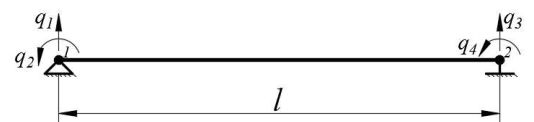

b)

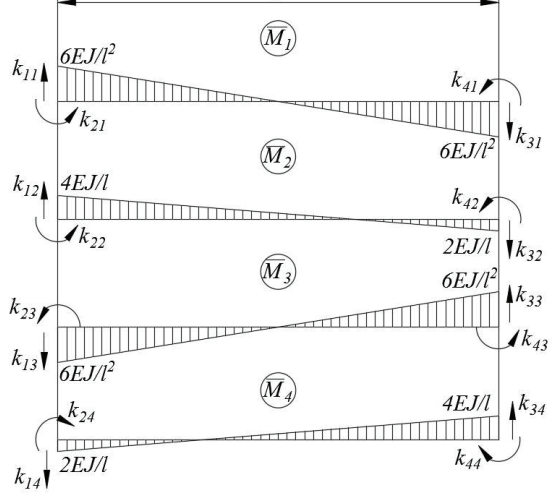

Fig. 1. Calculation scheme of beam FE ([1] with clarifications): a) depiction of unit displacement; b) reaction values at the joints of the FE. Designation: $l$ - length of FE; $q_{i}$ - unit displacement in direction $i ; k_{i j}$ - joint force in direction $i$ because of unit displacement $j ; \bar{M}_{j}$ - flexural moment diagram from a unit displacement

$$
q_{j}
$$

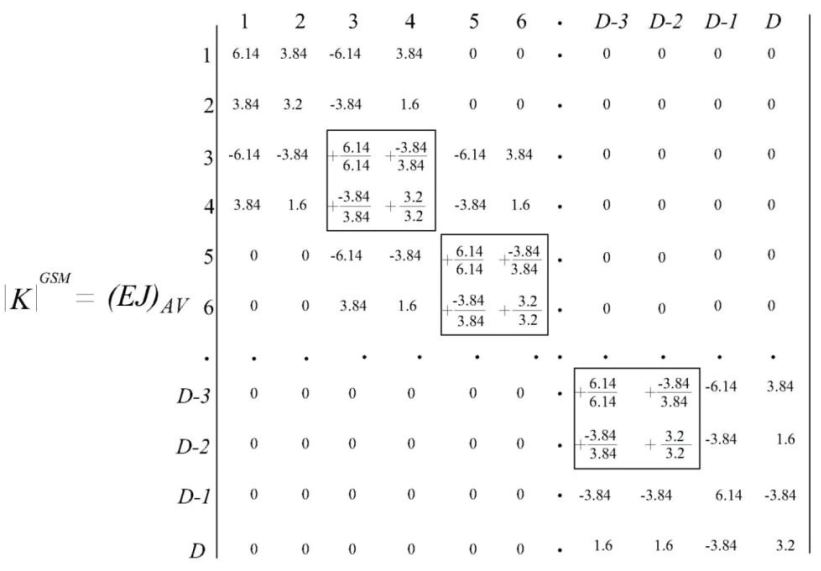

Fig. 2. Global stiffness matrix with average stiffness for all $\mathrm{FE}$ in a general form. Designations: $(E J)_{A V}-$ average flexural stiffness

In the works of many specialists compliance is defined as the inverse of system stiffness and equal to displacement of system point from the unit applied loads $[5,14]$. Then, to determine the compliance in all directions of deformations of FE system, it is necessary in Eq. (2.2) to take joint loads equal to 1, and to solve the resulting Eq. (2.4). 


$$
[K] \cdot \overrightarrow{q_{\imath}}=1
$$

After deriving displacement-vector $\vec{q}$ from FEM expression we get compliance in $i$-th direction of a system:

$$
\overrightarrow{q_{l}}=[K]^{-1} \cdot 1=\frac{1}{(E J)_{A V}} \cdot \overrightarrow{q_{l, 0}}
$$

Considering Eq. (2.1), Eq. (2.5) and assumption of interrelation resonant frequency with maximum compliance, the general formula for resonant frequency of natural oscillations for $\mathrm{FE}$ system [16]:

$$
\omega=\frac{1}{\sqrt{q_{i, m a x} \cdot m_{G}}}
$$

where:

$q_{i, \max }$ - Compliance in $i$-th direction of a system with maximum value; $m_{G}$ - mass of corresponding $G$-th FE. Mass $m_{G}$ can be replaced by moment of inertia $J_{m, G}$ in case of anguar deformations.

Consequently, from the Eq. (2.6) it is possible to derive the compliance value $q_{i, \max }$ :

$$
q_{i, \max }=\frac{1}{\omega^{2} \cdot m_{G}}
$$

Having replaced $q_{i, \max }$ by $\frac{1}{(E J)_{A V}} q_{i, 0, \max }$ (as in Eq. (2.5)), average flexural stiffness of a system for the adopted simplification will be:

$$
\begin{aligned}
& (E J)_{A V}=\left|q_{i, 0, \max }\right| \cdot \omega^{2} m, \\
& (E J)_{A V}=\left|q_{i, 0 . \max }\right| \cdot \omega^{2} J_{m} .
\end{aligned}
$$

Here Eq. (2.8) - formula for determining average flexural stiffness $(E J)_{A V}$ for the case of linear deformations with mass $m$ as an inertial characteristic; Eq. (2.9) — for the case of angular deformations with axial moment of inertia $J_{m}$ with the center in the joint $i$.

\section{VERIFICATION OF THE METHOD}

Verification of the method is carried out over numerical experiment with example of the beam on two supports (Fig. 3). The cross section is rectangular; the beam has a uniform stiffness along the length and 5 joints with concentrated masses in them. Degree of freedom of the whole system is 3 
since masses 1,5 are situated on supports, so the number of resonant frequencies is also 3 . The parameters of the structure under study are shown in Table 1. It's necessary to calculate the values of flexural stiffness and moment of inertia of the beam by FE method. Then compare the obtained values with the characteristics indicated in Table 1.

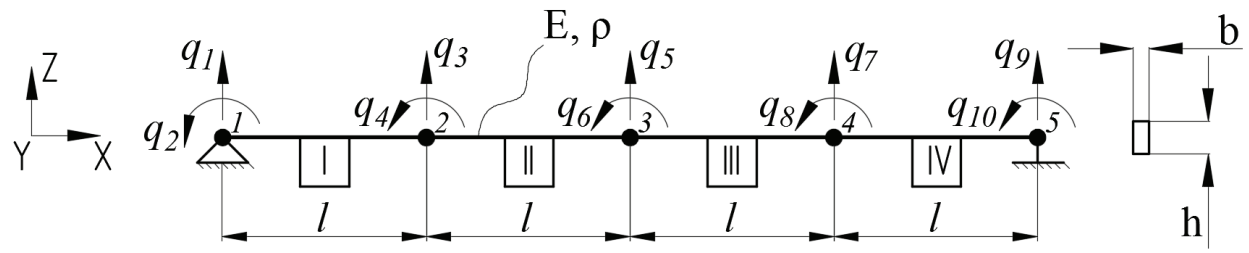

Fig. 3. Calculation scheme of the beam with finite element approximation and global numbering of displacements. Designations: I, II, III, IV — numbers of FE; 1,2,3,4 — joints of FE; * — dimensions in mm; $\mathrm{X}, \mathrm{Y}, \mathrm{Z}$ - axis identifications

Table 1 - Characteristics of the experimental beam*

\begin{tabular}{|c|c|c|c|}
\hline No & Parameter & Units of measurement & Value \\
\hline 1 & Material & - & Wood, pine II grade \\
\hline 2 & Module of elasticity $E$ & $\mathrm{MPa}$ & 10000 \\
\hline 3 & Density $\rho$ & $\mathrm{kg} / \mathrm{m}^{3}$ & 500 \\
\hline 4 & Width of cross-section $b$ & $\mathrm{~mm}$ & 100 \\
\hline 5 & Height of cross-section $h$ & $\mathrm{~mm}$ & 200 \\
\hline 6 & Finite element size $l$ & $\mathrm{~mm}$ & 1250 \\
\hline 6 & Moment of inertia of cross-section $J_{Y}$ & $\mathrm{~cm}^{4}$ & 6666.67 \\
\hline 8 & Flexural stiffness of cross-section $B_{Y}$ & $\mathrm{Nm}$ & 666667 \\
\hline 9 & First resonant frequency $\omega_{1}$ & $\mathrm{~Hz}(\mathrm{rad} / \mathrm{s})$ & $14.7(92.3)$ \\
\hline 10 & Second resonant frequency $\omega_{2}$ & $\mathrm{~Hz}(\mathrm{rad} / \mathrm{s})$ & $68.41(429.63)$ \\
\hline 11 & Third resonant frequency $\omega_{3}$ & $\mathrm{~Hz}(\mathrm{rad} / \mathrm{s})$ & $138.01(866.72)$ \\
\hline
\end{tabular}

* _ Values in accordance with GOST 8686-86 and SP 64.13330.2011 (Russian state standards).

The beam is divided into 4 finite elements and there are 5 joints with masses concentrated in them. It is necessary to fill 4 local stiffness matrices. The number of possible displacements in a joint and the number of joints determine the size of global stiffness matrix. In this case, the number of joints is 5 with transverse and angular displacement in each (Fig. 5). Size of the global stiffness matrix is $D=5 \times 2=5$. Flexural stiffness for each finite element $(E J)_{G}$ was replaced by one average flexural stiffness $(E J)_{A V}$, then local stiffness matrices for each finite element will be equal, since in this case the lengths $l$ of finite elements are equal. For ease of understanding, designation of the joint 
displacements $q_{i}$ is replaced by the linear transverse displacements $V_{i}$ and the angular displacements $\theta_{i}$. Next we can write down the basic FEM equation with taking into account boundary conditions of $V_{l}=0$ and $V_{5}=0$ (Fig. 4). Force values in the common joints of the system are outlined with square in matrix.

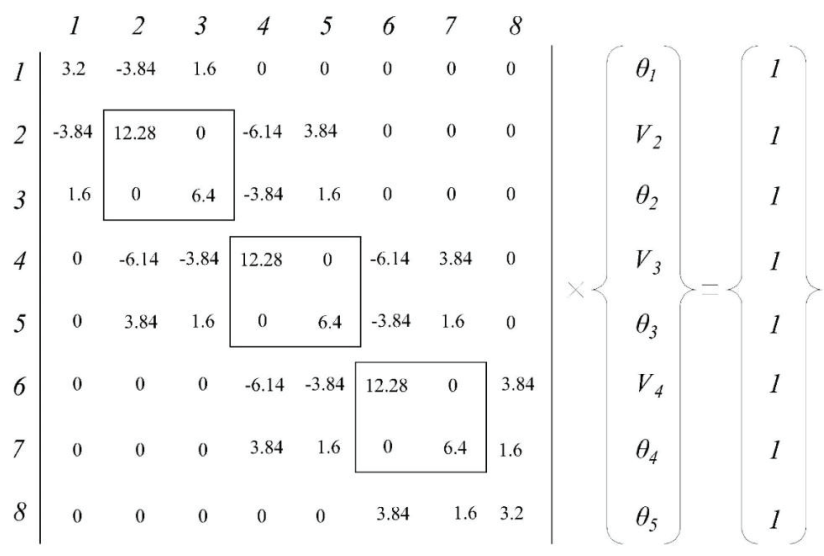

Fig. 4. Equation of the FEM for the considered beam with boundary conditions

For calculation of flexural stiffness, it is necessary to get inertial characteristics of the system. Calculate masses and moments of inertia of each joint and fill the corresponding matrices:

$$
m=\left|\begin{array}{l}
m_{1} \\
m_{2} \\
m_{3} \\
m_{4} \\
m_{5}
\end{array}\right|=\left|\begin{array}{l}
6.25 \\
12.5 \\
12.5 \\
12.5 \\
6.25
\end{array}\right| ; J_{m}=\left|\begin{array}{l}
J_{m_{1}} \\
J_{m_{2}} \\
J_{m_{3}} \\
J_{m_{4}} \\
J_{m_{5}}
\end{array}\right|=\left|\begin{array}{l}
0.81 \\
1.63 \\
1.63 \\
1.63 \\
0.81
\end{array}\right|
$$

where $m_{1}, m_{2}, m_{3}, m_{4}, m_{5}$ - masses concentrated at joints $1,2,3,4,5 ; J_{m_{1}}, J_{m_{2}}, J_{m_{3}}, J_{m_{4}}, J_{m_{5}}$ moments of inertia about masses 1, 2, 3, 4, 5.

\subsection{CALCUlation OVER THE FREQUENCIES}

Having solved the system of algebraic equations we get compliances in the joints (Table 2). Joint 3 of the beam has the maximum linear compliance $\mathrm{V}$ and joint 1 has maximum angular compliance. Then if we plot a graph over linear compliance values for the points 2, 3, 4 (Fig. 5, a), we'll get a curve close to the first form of beam oscillations. Thus, joint compliance allocation can define an oscillation form of a system. 
The results of calculating the flexural stiffness and the moment of inertia at the first frequency are listed in Table 2. In the Table 2 let's compare columns for every joint: 4-5 (calculated and factual flexural stiffness) and 7-8 (calculated and factual moment of inertia). As we can see, the minimum difference in $\%$ between the calculated and factual values was obtained at joint 3 over linear compliance; maximum linear compliance was observed also in this direction. The stiffness and moments of inertia at the rest joints and directions are not correct, since the difference with the actual values is more than $25 \%$. At the joint 1 , despite maximum value of angular compliance difference between calculated and factual stiffness is $95.37 \%$. Consequently, the frequency of natural oscillations of the structure system element is determined from the joint on the system with maximum linear compliance. The values in the remaining joints do not determine the first frequency $\omega_{1}$ and do not carry information from the point of view of determining the stiffness.

a)

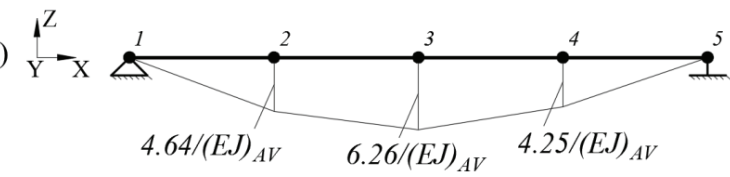

b)

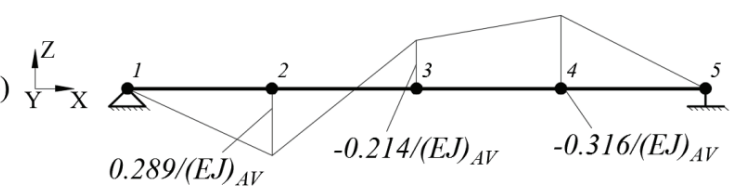

c)

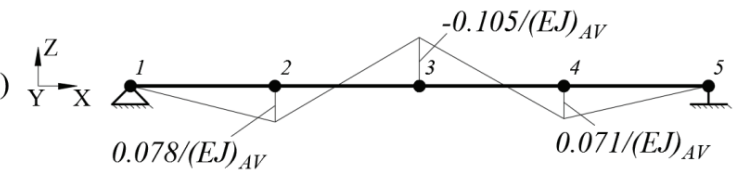

Fig. 5. Natural oscillation forms of the beam: a) First form; b) Second form; c) Third form

Table 2. Values of flexural stiffness and moment of inertia calculated over the first frequency.

Comparison with initial data values

\begin{tabular}{|c|c|c|c|c|c|c|c|c|}
\hline $\begin{array}{c}\text { No } \\
\text { joint }\end{array}$ & Direction & $\begin{array}{l}\text { Compliance, } \\
\mathrm{m} / \mathrm{N}(\mathrm{rad} / \mathrm{sec})\end{array}$ & $\begin{array}{c}\text { Calculated } \\
\text { flexural } \\
\text { stiffness } B_{Y}, \\
\mathrm{Nm}^{2}\end{array}$ & $\begin{array}{c}\text { Factual } \\
\text { flexural } \\
\text { stiffness } \\
B_{Y, 0}, \mathbf{N m}^{2} \\
\end{array}$ & $\begin{array}{c}\text { Difference, } \\
\%\end{array}$ & $\begin{array}{c}\text { Calculated } \\
\text { moment of } \\
\text { inertia } J_{Y}, \mathbf{c m}^{4}\end{array}$ & $\begin{array}{c}\text { Factual } \\
\text { moment of } \\
\text { inertia } \\
J_{Y, 0}, \mathbf{c m}^{4}\end{array}$ & $\begin{array}{c}\text { Difference, } \\
\%\end{array}$ \\
\hline 1 & 2 & 3 & 4 & 5 & 6 & 7 & 8 & 9 \\
\hline 1 & $\theta_{1}$ & $4.475 /(E J)_{A V}$ & 30880 & \multirow{4}{*}{666667} & 95.37 & 308.8 & \multirow{4}{*}{6666.67} & 95.37 \\
\hline \multirow{2}{*}{2} & $V_{2}$ & $4.644 /(E J)_{A V}$ & 494119 & & 25.89 & 4941.19 & & 25.89 \\
\hline & $\theta_{2}$ & $2.82 /(E J)_{A V}$ & 39160 & & 94.13 & 391.6 & & 94.13 \\
\hline 3 & $V_{3}$ & $6.26 /(E J)_{A V}$ & 666634 & & $<0,01$ & 6666.34 & & $<0,01$ \\
\hline
\end{tabular}




\begin{tabular}{|c|c|c|c|c|c|c|}
\hline & $\theta_{3}$ & $-0.11 /(E J)_{A V}$ & 1458 & $>99$ & 14.58 & $>99$ \\
\hline \multirow{2}{*}{4} & $V_{4}$ & $4.252 /(E J)_{A V}$ & 452587 & 32.11 & 4525.87 & 32.11 \\
\hline & $\theta_{4}$ & $-2.72 /(E J)_{A V}$ & 37716 & 94.34 & 377.16 & 94.34 \\
\hline 5 & $\theta_{5}$ & $-3.43 /(E J)_{A V}$ & 23683 & 96.45 & 236.83 & 96.45 \\
\hline
\end{tabular}

As a result, we get average value of flexural stiffness of the all system by the first resonant frequency of natural oscillations $\omega_{1}$. To calculate the stiffness with respect to the second natural frequency $\omega_{2}$, consider the total energy of the elastic oscillations in the joints $2,3,4$ at the first frequency $\omega_{1}$. In this case, we replace the oscillation amplitude by the compliance $V$ for the case of unit loads: $E_{2}=\frac{m_{2} V_{2}^{2} \omega_{1}^{2}}{2} ; E_{3}=\frac{m_{3} V_{3}^{2} \omega_{1}^{2}}{2} ; E_{4}=\frac{m_{4} V_{4}^{2} \omega_{1}^{2}}{2}$. The masses of joints $2,3,4$ are equal, but the compliances are different, therefore, depending on the compliance values at these points, the following will be true: $E_{\max }>E_{\max -1}>E_{\max -2}$. Here $E_{\max }$ - the oscillation energy at the point with the maximum compliance from the three points considered $2,3,4 ; E_{\max -1}-$ the energy of oscillations at the point with the following in the direction of decrease by the compliance value; $E_{\max -2}$ - the oscillation energy at the point with the minimum compliance from the three points considered 2,3,4. To appearance the second form of oscillations, the following conditions must be met:

$$
E_{\max -2}, E_{\max -1} \geq E_{\max }
$$

This condition can only be fulfilled if the point with $E_{\max }$ is immovable. Therefore, at a vibration frequency $\omega_{2}$, the linear displacements of the $V$ point with $E_{\max }$ will be zero. Thus, to calculate the maximum compliance for oscillations at the second frequency $\omega_{2}$ and the second form, it is necessary to assign boundary conditions for which the point with $E_{\max }$ has zero linear displacements. To this end, in accordance with FEM, it is necessary to remove from the global stiffness matrix of construction rows and columns with numbers of vertical displacement at the point with $E_{\max }$.

To perform the second cycle of calculations for $\omega_{2}$, we assign boundary conditions with allowance for linear immobility of joint with maximum energy (in this case that is joint 3 with linear deformations). The results of calculating flexural stiffness over the second frequency $\omega_{2}$ are presented in Table 3.

Table 3. Values of flexural stiffness and moment of inertia calculated over the second frequency. 


\begin{tabular}{|c|c|c|c|c|c|c|c|c|}
\hline $\begin{array}{c}\text { No } \\
\text { joint }\end{array}$ & Direction & $\begin{array}{c}\text { Corresponding } \\
\text { linear compliance, } \\
\mathbf{m} / \mathbf{N}\end{array}$ & $\begin{array}{c}\text { Calculated } \\
\text { flexural } \\
\text { stiffness } B_{Y}, \\
\mathrm{Nm}^{2} \\
\end{array}$ & $\begin{array}{c}\text { Factual } \\
\text { flexural } \\
\text { stiffness } \\
B_{Y, 0}, \mathrm{Nm}^{2} \\
\end{array}$ & $\begin{array}{c}\text { Difference, } \\
\%\end{array}$ & $\begin{array}{c}\text { Calculated } \\
\text { moment of } \\
\text { inertia } J_{Y}, \\
\text { cm }^{4} \\
\end{array}$ & \begin{tabular}{|c|} 
Factual \\
moment of \\
inertia \\
$J_{Y, 0}, \mathbf{c m}^{4}$ \\
\end{tabular} & $\begin{array}{c}\text { Difference, } \\
\%\end{array}$ \\
\hline 1 & 2 & 3 & 4 & 5 & 6 & 7 & 8 & 9 \\
\hline 1 & $\theta_{1}$ & $0.665 /(E J)_{A V}$ & 99425 & \multirow{7}{*}{666667} & 85.09 & 994 & \multirow{7}{*}{6666.67} & 85.09 \\
\hline \multirow{2}{*}{2} & $V_{2}$ & $0.289 /(E J)_{A V}$ & 666805 & & $<0.01$ & 6668 & & $<0.01$ \\
\hline & $\theta_{2}$ & $-0.01 /(E J)_{A V}$ & 3009 & & $>99$ & 31 & & $>99$ \\
\hline 3 & $\theta_{3}$ & $-0.057 /(E J)_{A V}$ & 17150 & & 97.43 & 172 & & 97.43 \\
\hline \multirow{2}{*}{4} & $V_{4}$ & $-0.031 /(E J)_{A V}$ & 71526 & & 89.27 & 715 & & 89.27 \\
\hline & $\theta_{4}$ & $0.095 /(E J)_{A V}$ & 28583 & & 95.71 & 286 & & 95.71 \\
\hline 5 & $\theta_{5}$ & $0.302 /(E J)_{A V}$ & 45152 & & 93.23 & 451 & & 93.23 \\
\hline
\end{tabular}

The maximum linear compliance at this stage of calculation is observed at the joint 2 of the beam; the maximum angular compliance is observed at joint 1 . At the same time the minimum difference in $\%$ between calculated and actual values was obtained only at the joint 2 over linear direction. To construct forms of natural oscillations at the second frequency $\omega_{2}$, we must take into account their orthogonality property which performs as follows [13]:

$$
\left(\omega_{1}^{2}-\omega_{2}^{2}\right)\left[m_{1} A_{11} A_{12}+m_{2} A_{21} A_{22}\right]=0,
$$

where:

$\omega_{1}$ - first resonant frequency; $\omega_{2}-$ second resonant frequency; $m_{1}-$ system mass in point 1 ; $m_{2}$ - system mass in the point $2 ; A_{11}$ - amplitude in point 1 with frequency $\omega_{1} ; A_{12}$ - amplitude in point 1 with frequency $\omega_{2} ; A_{21}-$ amplitude in point 2 with frequency $\omega_{1} ; A_{22}-$ amplitude in point 2 with frequency $\omega_{2}$. If $\omega_{1} \neq \omega_{2}$ (basic case), and if to replace amplitude $A$ to displacement from single load (compliance $\delta$ ), then we get:

$$
m_{1} \delta_{11} \delta_{12}+m_{2} \delta_{21} \delta_{22}=0
$$

After clarification of compliance $V$ in joints 3, 4, we get a second form of natural oscillations (Fig. $5, b)$.

To get flexural stiffness from the third frequency $\omega_{3}$, we repeat algorithm: complement boundary conditions from second cycle of calculation with allowance for the linear immobility of joint with maximum energy (joint 2 over linear deformations). Joints 2, 3 now have a nominal supports.

Table 4. Values of flexural stiffness and moment of inertia calculated over the third frequency. 


\begin{tabular}{|c|c|c|c|c|c|c|c|c|}
\hline $\begin{array}{c}\text { No } \\
\text { joint }\end{array}$ & Direction & $\begin{array}{c}\text { Corresponding } \\
\text { linear compliance, } \\
\mathbf{m} / \mathbf{N}\end{array}$ & $\begin{array}{c}\text { Calculated } \\
\text { flexural } \\
\text { stiffness } B_{Y}, \\
\mathrm{Nm}^{2} \\
\end{array}$ & $\begin{array}{c}\text { Factual } \\
\text { flexural } \\
\text { stiffness } \\
B_{Y, 0, N^{2}} \\
\end{array}$ & $\begin{array}{c}\text { Difference, } \\
\%\end{array}$ & $\begin{array}{c}\text { Calculated } \\
\text { moment of } \\
\text { inertia } J_{Y}, \\
\text { cm }^{4}\end{array}$ & \begin{tabular}{|c|} 
Factual \\
moment of \\
inertia \\
$J_{Y, 0}, \mathbf{c m}^{4}$ \\
\end{tabular} & $\begin{array}{c}\text { Difference, } \\
\%\end{array}$ \\
\hline 1 & 2 & 3 & 4 & 5 & 6 & 7 & 8 & 9 \\
\hline 1 & $\theta_{1}$ & $0.268 /(E J)_{A V}$ & 163071 & \multirow{6}{*}{666667} & 75.54 & 1631 & \multirow{6}{*}{6666.67} & 75.54 \\
\hline 2 & $\theta_{2}$ & $0.089 /(E J)_{A V}$ & 108977 & & 83.65 & 1090 & & 83.65 \\
\hline 3 & $\theta_{3}$ & $0.159 /(E J)_{A V}$ & 196689 & & 70.5 & 1967 & & 70.5 \\
\hline \multirow{2}{*}{4} & $V_{4}$ & $0.071 /(E J)_{A V}$ & 666693 & & $<0.1$ & 6666.93 & & $<0.1$ \\
\hline & $\theta_{4}$ & $0.068 /(E J)_{A V}$ & 82263 & & 87.66 & 823 & & 87.66 \\
\hline 5 & $\theta_{5}$ & $0.194 /(E J)_{A V}$ & 118044 & & 89.29 & 1180 & & 89.29 \\
\hline
\end{tabular}

The maximum linear compliance at this stage of calculation is observed at the joint 4 of the beam; maximum angular compliance - at the joint 1 . At the same time the minimum difference in $\%$ between calculated and actual values was obtained only at the joint 4 over linear direction. Having used orthogonality property, we get third form of natural oscillations (Fig. 5, c).

So, over the known frequencies, it is possible to determine only average flexural stiffness, since in calculating at different frequencies the same equations are considered, but with different boundary conditions. As we see from paragraph 3, quantity of unknowns in the global stiffness matrix is always $G$ (where $G$ is the number of finite elements), while the input value of the natural frequency is one. Thus, it is not possible to determine the stiffness in each FE.

However, if we take the values of compliances $\vec{q}$ as the input data for solving such a problem, then the number of unknowns will be less than the number of elements in the column $\vec{q}$ by $G / D$ times ( $D$ is the number of displacements in the model, the number of rows in the GSM), and the problem will be possible to solve. Compliances at key points of a structure can be determined by the method of forced oscillations [16], which implies the use of a digital harmonic oscillator. This method is time consuming and requires further research in the application of it to solve the problem considered. Nevertheless, obtaining information about the flexural stiffness (and, in fact, bearing capacity) at any desired point of the structure gives a significant reserve for the development of vibration methods for diagnosing the technical condition of construction projects.

\section{Conclusions}

The method for calculation flexural stiffness and moment of inertia of the cross section according to the given values of resonant frequencies is considered. The algorithm for estimation of these parameters by the FEM is developed, in particular, the algorithm for calculating stiffness and 
moment of inertia at basic and higher frequencies. Verification of the method is conducted on example of the beam on two supports. Forms of natural oscillations are verified with results in the LIRA CAD software package.

The results of the work lead to the following conclusions.

1. Calculation of resonant frequency and, conversely, flexural stiffness and moment of inertia is possible only for the joint with maximum compliance of a system.

2. At resonance frequency, it is possible to determine only the average stiffness in the direction in question.

3. In order to calculate stiffness at second and higher frequencies, it is required to fix the linear movements of the previous point with maximum compliance. To do this, the boundary conditions for a system are supplemented; rows and columns with the number of the given point are deleted additionally from the global stiffness matrix.

4. For getting natural oscillation forms, it is necessary to clarify compliance values, which is gained in every stage of calculation, by orthogonality property.

The considered algorithm is the basis of software for analysis actual stiffness and residual life of building and structures. The evolution prospect of this algorithm lies in the development of instrumental diagnosis of buildings and structures. One of directions in development is an experimental determination of compliance in required joints of a surveyed structure and introduction of values into the calculation of actual stiffness. This makes it possible to analyze flexural stiffness in more detail. Analysis of defects and damages, as well as comparison of the actual flexural stiffness and moment of inertia with their design values, allows analyzing the operational reliability of construction object with sufficient accuracy, which will significantly increase the safety of its operation and reduce the material costs for reinforcement or reconstruction.

\section{REFERENCES}

1. Strange G., Fix G.J. An analysis of Finite Element Method. Wellesley-Cambridge; 2nd edition. 2008. P. 414 (eng).

2. Kamgar R., Rahgozar R. A simple approximate method for free vibration analysis of framed tube structures // The Structural Design of Tall and Special Buildings. 2013. Vol. 22. No 2. Pp. 217-234.

3. S. Miyamoto. A study on seismic performance and seismic diagnosis, seismic retrofit of Japanese temple / S. Miyamoto, K. MIYAZAWA, Ya. IRIE, J. Wu, Yo. Nomata, Os. Goto // 13th World Conference on Earthquake Engineering. Vancouver, B.C., Canada. August 1-6, 2004. Paper No. 853 (eng).

4. Volkovas, V. Diagnostics of construction defects in a building by using time-frequency analysis / V. Volkovas, K. Petkevičius, M. Eidukevičiütè, T.C. Akinci // MECHANIKA, 2012 Volume 18(4): 432-437 (eng).

5. Kotlyarevskiy V.A. Diagnostika skrytykh defektov seysmostoykikh sooruzheniy po izmeneniyu chastotnogo spektra [Diagnosis of hidden defects of seismic resistant structures by changing the frequency spectrum]. Seysmostoykoye stroitelstvo. Bezopasnost sooruzheniy [Seismic resistant construction. Safety of buildings.]. 2014. No 4. Pp. 36-42. (rus). 
6. Ghorbe O., Casimir J.B., Hammami L., Tawfig I., Haddar M. Dynamic stiffness formulation for free orthotropic plates // Journal of Sound and Vibration. 2015. № 346. Pp. 361-375.

7. Zhadanov V.I., Nesterenko A.M., Nesterenko M.Yu., Stolpovskiy G.A. Issledovaniye pogloshchayushchikh svoystv materiala stroitelnykh konstruktsiy na primere zhelezobetonnoy peremychki [Study of absorbing properties of construction materials: concrete bulkhead case study] / Izvestiya vysshikh uchebnykh zavedeniy. Stroitelstvo [News of higher educational institutions. Construction], Novosibirsk. No 9 (693), 2016. Pp. 76-86. (rus).

8. Kapustyan N.K. Kompleks inzhenerno-seysmometricheskikh metodik dlya otsenki sostoyaniya zdaniy i sooruzheniy [Complex of engineering seismometric techniques for assessing the condition of buildings and structures]. Kapustyan N.K. [and others]. Nauka i bezopasnost [Science and Safety]. No 5, June-August, 2012. (rus).

9. Gorodetskiy A.S., Lazarev A.A. LIRA-SAPR — programmnyy kompleks dlya rascheta i proyektirovaniya stroitelnykh konstruktsiy razlichnogo naznacheniya [LIRA-SAPR - software for calculating and designing building structures for various purposes]. Novyye kompyuternyye tekhnologii [New computer technologies]. 2011. Vol. 9. No 1 (9). Pp. 22-26. (rus)

10. Peterson J. Observations and modeling of seismic background noise // Open-File Rep. Albuquerque. New Mexico. 1993. P.93-322 (eng).

11. Nesterenko M.Yu., Nesterenko A.M. Obsledovaniye zdaniy i sooruzheniy metodom seysmicheskogo zondirovaniya [Survey of buildings and structures using the method of seismic sounding]. Elektronnyy zhurnal "Byulleten Orenburgskogo nauchnogo tsentra" [E-magazine "Bulletin of the Orenburg Scientific Center"]. No 2/2014. P. 5. (rus).

12. Tyukalov Yu. Ya. Opredelenie chastot svobodnyh kolebanij metodom konechnyh elementof v napryazheniyah [Stress finite element models for determining the frequencies of free oscillations] / Magazine of Civil Engineering. 2016. No 7 (67). Pp. 39-54.

13. A. Branski. Modes Orthogonality of the Mechanical System Simple Supported Beam Actuators Concentrated Masses // ACTA PHYSICA POLONICA A. Vol. 121 (2012). No 1-A.

14. Korobko, V.I., Chernyaev A.A. Reshenie zadach poperechnogo izgiba plastinok s ispolzovaniem konformnyh radiusov [Solution of the problems of transverse bending of plates with the use of conformal radii]. Stroitelnaya mehanika I raschet sooruzhenij [Construction mechanics and design of structures]. 2011. No. 6. Pp. 16-22 (rus).

15. L. Crainic. Seismic performance of Concrete Buildings / L. Crainic, M. Munteanu // Structures and Infrastructures Series: ISSN 1747-77735, Volume 9 (eng).

16. Cyril M. Harris and Charles E. Crede. Shock and vibration handbook. McGraw-Hill Book Company, Inc. 1976 (eng).

17. Gienke E.A. Simple "mixed" method for plate and shell problems // Nuclear Engineering and Design. 1974. Vol. 29. No 1. Pp. 141-155.

18. Volkovas, V. The concept of buildings stability monitoring and damage diagnostics. Key Engineering Materials, 2013 (eng).

19. Trampczynski, W. 56Th Scientific Conference of Committee for Civil Engineering of the Polish Academy of Sciences and Scientific Committee of the Polish Association of Civil Engineers and Technicians Krynica, Poland // Archives of Civil Engineering, LVI, 4, 2010.

\section{LIST OF FIGURES AND TABLES:}

Fig. 1. Calculation scheme of beam FE

Fig. 2. Global stiffness matrix with average stiffness for all FE in a general form

Fig. 3.Calculation scheme of the beam with finite element approximation and global

Table 1. Characteristics of the experimental beam

Fig. 4. Equation of the FEM for the considered beam with boundary conditions

Fig. 5. Natural oscillation forms of the beam

Table 2. Values of flexural stiffness and moment of inertia calculated over the first frequency

Table 3. Values of flexural stiffness and moment of inertia calculated over the second frequency

Table 4. Values of flexural stiffness and moment of inertia calculated over the third frequency 


\section{METHOD OF CALCULATION FLEXURAL STIFFNESS OVER NATURAL OSCILLATIONS FREQUENCIES}

Keywords: dynamics, building system, frequency of natural oscillations, flexural stiffness, finite-element method

\section{SUMMARY:}

The actual load-bearing capacity of elements of a building system, including flexural stiffness and moment of inertia of the cross section, can be calculated by dynamic parameters, in particular the resonant (natural) frequency and compliance. The prerequisites for solving such a problem by the finite element method (FEM) are presented in the article. First, modern vibration tests demonstrate high accuracy in determination of these parameters, which reflects reliability of the diagnosis. Secondly, most modern computational complexes do not include a functional for calculating the load-bearing capacity of an element according to the input values of resonance frequencies. Thirdly, FEM is the basis for development of software tools for automating the computation process. The article presents the method for calculating flexural stiffness and moment of inertia of a beam construction system at its own frequencies. The method includes calculation algorithm realizing the finite element method. The performed studies revealed the dependence of the value of the natural frequency, flexural stiffness and moment of inertia from the joint of a beam with maximum linear compliance. It is proved that it is possible to determine the average stiffness in the considered direction at the resonant frequency, and the number of resonant frequencies is not related to the number of points of the system where it is possible to determine flexural stiffness. The algorithm for calculating stiffness at the second and higher frequencies is obtained. In order to calculate stiffness at the second and higher frequencies, it is required to fix linear movements of the previous point with maximum compliance. To do this, the boundary conditions for the system are supplemented and rows and columns with the number of the given point are deleted additionally from the global stiffness matrix. The approach for constructing vibration modes is obtained from the compliance values. For getting natural oscillation forms, it is necessary to clarify compliance values, which is gained in every stage of calculation, by orthogonality property. Verification of the method is made by numerical experiment with beam on two supports. There is comparison of the vibration modes constructed from compliance values with the ones gained from modelling in calculation complex. The evolution prospect of this algorithm lies in the development of instrumental diagnosis of buildings and structures. One of directions in development is an experimental determination of compliance in required joints of the surveyed structure and introduction of the values into the calculation of actual stiffness. 